\title{
CITATION PATTERNS IN MIS: An Analysis of Exemplar Articles
}

\author{
Tor J. Larsen ${ }^{\dagger}$ \\ Department of Leadership and Organizational Management \\ Norwegian School of Management \\ Oslo, Norway \\ Linda Levine ${ }^{\dagger}$ \\ Software Engineering Institute \\ Carnegie Mellon University \\ Pittsburgh, PA U.S.A.
}

\begin{abstract}
The present research examines MIS exemplar articles, analyzing their citation patterns in MIS and other scientific fields. Using MIS Quarterly articles of the year and peer-nominated articles, we identified 36 exemplar MIS articles. In all, 421 journals contained articles that cited the exemplars. Our five findings are: (1) the MIS exemplars cover a wide range of themes, (2) the average lifetime for an exemplar article (as expressed through the citations made to the article) is 17 years, as compared with an 11 year expected life time for scientific journal articles, (3) the dominant life-cycle pattern for an exemplar takes the form of a bell curve, (4) exemplar articles that were conceptual in nature are not cited any more frequently than articles treating contemporary issues, and (5) conceptual contributions have a longer lifetime of citation activity than contemporary exemplars. Future research will more closely examine MIS and its reference disciplines, as is revealed through extensive citation analysis of the exemplars.
\end{abstract}

Keywords Citation analysis, bibliometrics, scientometrics, diffusion of research, exemplar articles, MIS research agenda

\footnotetext{
${ }^{\dagger}$ The authors are listed in alphabetical order but have contributed equally to the article.
}

Please use the following format when citing this chapter:

Larsen, T. J., and Levine, L., 2008, in IFIP International Federation for Information Processing, Volume 287, Open IT-Based Innovation: Moving Towards Cooperative IT Transfer and Knowledge Diffusion, eds. León, G., Bernardos, A., Casar, J., Kautz, K., and DeGross, J. (Boston: Springer), pp. 23-38. 


\section{INTRODUCTION}

The evolution of the discipline of Management Information Systems (MIS) ${ }^{1}$ has been discussed by Baskerville and Myers (2002) and explored through empirical analyses of journals and citation patterns (Grover et al. 2006a, 2006b; Holsapple et al. 1994; ISWorld $^{2}$; Mylonopoulos and Theoharakis 2001; Pfeffers and Ya 2003; Straub 2006; Vessey et al. 2002; Wade et al. 2006a, 2006b; Walstrom and Hardgrave 2001). These publications build on the notion that MIS continuously borrows ideas and findings from other fields, in the spirit of innovation and exchange (Culnan 1986; Davis 2000). As the body of knowledge has grown, MIS articles have come to cite other MIS publications more frequently, and thus the field has evolved into a more mature academic discipline (Cheon et al. 1993; Culnan and Swanson 1986; Katerattakanakul et al. 2006), creating its own body of research. In tandem, in the discipline of information science, researchers continue to examine and debate the appropriateness, value, and methods of citation analysis in its own right (Bauer and Bakkalbasi 2005; Garfield 1987; Jacso 2005; Perkel 2005).

Ongoing discussion has focused on the nature of the MIS core and subareas (Larsen and Levine 2005). Orlikowski and Baroudi (1991) argue that MIS research exhibits a single set of philosophical assumptions regarding the nature of the phenomena studied, and what constitutes valid knowledge about these phenomena. Weber (1987) claims that MIS consists of multiple areas of activity, each employing its own theories, which are to a large extent borrowed from other scientific fields. In Weber's view, there is no unified theory of MIS; he asserts that the field will not make theoretical advancements until a paradigm is developed. Orlikowski and Iacono (2001) reinforce these concerns. They question the identity of MIS and claim that scientific progress cannot be made without a unified theory of the IS/IT artifact. Further attempts have been made to define and circumscribe the IT artifact (Benbasat and Zmud 2003; Larsen 1998; Orlikowski and Iacono 2001; Whinston and Geng 2004). Some view the diversity in MIS as a problem (Benbasat and Weber 1996), while others see diversity and openness as providing fertile ground for research in subfields of MIS (Ives et al. 2004; Lyytinen and King 2004; Myers 2002; Robey 1996; Weber 2003). Additionally, MIS and its subfields are of interest to many other scientific fields (Davis 2000). This lends support to Baskerville and Myers' (2002) claim that MIS has matured into a bona fide source of reference for researchers in other scientific fields.

The present investigation is the first step in a research project concerned with the use of MIS research publications in the field of MIS and in other fields. Such empirical research addressing the use of scientific publications commonly employs citation analysis. Small $(1973,1978)$ observes that a citation is evidence of acceptance of meaning and

${ }^{1}$ Different labels are used to refer to the field, for example: Information Technology (IT), Information Communication Technology (ICT), Information Systems (IS), Management Information Systems (MIS), and Information Management (IM). Knowledge Management Systems (KMS) is another term that is increasingly in use. Each term has its proponents; however, the terms are often used interchangeably. For the sake of clarity and consistency, we use the term Management Information Systems.

${ }^{2}$ Located at http://home.aisnet.org. 
is viewed as a standard symbol for ideas represented in the text. Any analysis of citations requires a dataset. Our investigation employs a set of exemplar MIS articles. Using MIS Quarterly "articles of the year" and peer-nominated articles, we identified 36 MIS exemplars. These are not "exemplars" in Kuhn's (1970) sense, where exemplars serve as the foundation of a paradigm. Rather, our exemplars are illustrative of important contributions in the field of MIS. This leads us to the following research question:

\section{How are these exemplar MIS articles cited in the field of MIS and other fields?}

The first phase of this research is focused on citation analysis and citation patterns of the exemplars - not on making distinctions among scientific fields. Future research will more closely examine MIS and its reference disciplines, as is revealed through more extensive citation analysis of the exemplars. The present article proceeds to cover background and propositions, method, analysis, discussion, and conclusions.

\section{BACKGROUND AND PROPOSITIONS}

Our research question rests on two assumptions: (1) that science can be distinctly separated into fields, each with its own recognized scientific journals; and (2) that MIS is recognized as a field. Kuhn (1970) defines a scientific field as distinct (from other sciences) when a high level of consensus about a paradigm, shared theoretical structures, and commonly applied methodological approaches can be found.

According to Ritzer (1975), a paradigm consists of four basic components: (1) a model to be emulated, (2) an image of the subject matter, (3) theories, and (4) methods and instruments. Pfeffer (1993) suggests that the maturity of paradigm development in a field is dependent upon 14 elements, including social ties, departmental issues, faculty, and publication. These elements have not been systematically investigated in MIS. However, researchers concur that a common set of agreed upon theories derived from a paradigmatic platform does not exist in MIS (Agarwal and Lucas 2005; Benbasat and Weber 1996; Monod and Boland 2007; Orlikowski and Iacono 2001; Weber 2003). For the most part, MIS is seen as a field without a dominant paradigm.

An additional qualification is in order. The concept of paradigm, as Kuhn defines it, is derived from research in the physical sciences. This perspective may not serve well in the social sciences, where pluralistic models are more appropriate as the basis for understanding and analysis (Banville and Landry 1989). Given that MIS is a social science, multiple theories and approaches compete for attention and status (Avison et al. 2001; Benbasat and Weber 1996; Davis 2000; Robey 1996; Weber 1987). Thus, researchers contend that diversity and rival interpretations are the rule in MIS (Benbasat and Zmud 2003; Ives et al. 2004; Whinston and Geng 2004).

In keeping with this view, a set of articles deemed important to the field of MIS would cover a range of themes and theories (Alavi and Carlson 1992). Indeed, Baskerville and Myers (2002) declare (Table 1, p. 4) that research contributions in MIS include five bodies of knowledge, each with concepts, theories, processes, and applications. 
Proposition 1: A set of exemplar MIS articles covers a wide range of themes.

To further our investigation into these exemplar MIS articles, and the range of themes and theories that are expressed, we perform an analysis of citation patterns. In particular, we attend to these patterns over time, in order to discern the prospect of a citation life cycle of the exemplar articles:

Proposition 2a: The average expected life time for a journal article (as expressed through the citations made to the article), is 11 years (Kronman 2007). Since an exemplar is outstanding by definition, the average life time is expected to exceed 11 years.

Proposition 2b: The dominant life cycle pattern for an exemplar article will take the form of a bell curve, illustrating the following shape over time: increase in number of citations, plateau/peak, and, finally, decrease.

Proposition 2c: Within the set of exemplars, we expect that articles that reflect conceptual contributions (e.g., theory and research methods) will be cited more frequently than articles that treat contemporary or "hot" issues (e.g., specific approaches and methods in consulting, or technology platforms and environments).

Proposition 2d: Within the set of exemplars, we expect that articles that reflect conceptual contributions will have a longer lifetime of citation activity than exemplars that treat contemporary or hot issues.

\section{METHOD}

Citation analysis involves several types of study, including direct citation, co-citation analysis, and bibliographic coupling. ${ }^{3}$ Small (1973) observes that direct citation- the citing of an earlier document by a new document - and bibliographic coupling have received considerable attention. Bibliographic coupling links source documents. However, in measuring co-citation strength, researchers measure the degree of relationship or association between papers as perceived by the population of citing authors. Furthermore, because of this dependence on the citing authors, these patterns can change over time, just as vocabulary co-occurrences can change as subject fields evolve (Small 1973,

${ }^{3}$ Citation analysis should not be confused with classification analysis. Classification studies constitute one of the major approaches to investigating patterns in research (Vessey et al. 2002, 2005). One specific instance employs meta-analysis techniques. Meta-analysis uses the common variables and relationships in empirical data to discern general and overarching patterns across different studies. Another classification approach takes a broader perspective and consists of analysis of topic or subject matter. This process involves selecting a topic and reviewing many journals and conference proceedings in order to find evidence of patterns, trends, similarities, and differences. The articles considered in a topical analysis may be either quantitative or qualitative and need not adhere to any common method (Larsen and Levine 2007). 
p. 265). Small observes that many information scientists focus attention on the operation of document retrieval systems serving scientists in various fields. The scientists who are served by these systems comprise an invisible college (Crane 1972) - networks of scientists "in frequent communication with one another and involved with highly specialized subject matters" (Small 1980, p. 183).

Culnan and Swanson (1986) use citation analysis to measure how MIS is evolving as a standalone discipline separate from its foundation disciplines of computer science, management science, and organization behavior. Their analysis studied 271 articles across seven outlets (six journals and one conference proceedings) over the period of 1980-1984. They concluded that (1) MIS remains less established than its foundation disciplines, (2) MIS is growing and maturing in terms of output and cited references, and (3) there is no consensus as to a body of work integral to the field. Culnan (1986) examines trends in MIS research, and observes that MIS management issues have emerged as a subfield. Moreover, the traditional emphasis on technology and technical issues has been displaced by a strong organizational and managerial focus. Culnan considers the intellectual structure of MIS research and, based on co-citation analysis, she identifies five invisible colleges (or informal clusters of research activity): foundations, psychological approaches to MIS design and use, MIS management, organizational approaches to MIS design and use, and curriculum.

Citation analysis remains a popular means to investigate the nature of the discipline. For example, Katerattanakul and Hong (2003) assess the quality of MIS Quarterly and compare this assessment to other journals of other disciplines. They conclude that MISQ ranks favorably in comparison with specialty journals and respectably among general journals (of specific disciplines). More recently, Straub (2006) summarizes citation research activity and comments on its contribution to understanding the evolution of the discipline.

In creating our own citation data, we employed four steps: (1) we defined a portfolio of exemplar MIS articles, (2) we identified any articles which cited these exemplars, (3) we prepared data for keyword analysis of exemplar articles, and (4) we prepared the citation data, including the analysis of life-cycle patterns. These steps are described below in chronological order.

\section{Step 1: Defining a Portfolio of Exemplar MIS Articles}

While many reports on journal quality and ranking exist (Pfeffers and Ya 2003), we were unable to locate a definitive list of classic or seminal MIS articles. We employed two approaches for compiling our list of exemplar MIS articles: (1) award winning articles and (2) evaluation by peers. First, our sample of award winning articles was drawn from MIS Quarterly "articles of the year" and Society for Information Management (SIM) competition-winner articles. Some might criticize the inclusion of SIM articles; however, the ongoing debate on the relevance of MIS indicates that practitioneroriented material is important. Similarly, MIS Quarterly no longer distinguishes between "practice" and "science" articles.

For the period 1993-1999, MISQ named eight articles of the year. For the period 1994-2000, five SIM competition articles were named. Henceforth, these are referred to as "award articles." 
Table 1. Peer-Nominated Articles and the Journals in Which They Appear

\begin{tabular}{|c|l|}
\hline $\begin{array}{c}\text { \# of Peer } \\
\text { Nominated } \\
\text { Articles }\end{array}$ & \\
\hline 7 & MIS Quarterly \\
\hline 6 & Management Science \\
\hline 3 & Communications of the ACM Title \\
\hline 2 & IBM Systems Journal \\
\hline 2 & Information Systems Research \\
\hline 1 & Accounting, Management and Information \\
\hline 1 & European Journal of Information Systems \\
\hline 1 & Harvard Business Review \\
\hline
\end{tabular}

Note: The data for this table are based on entries 14 through 36 in Appendix A.

Second, we reflected that peers might have their personal MIS research article favorites. We identified 17 peers who were well known in the community. ${ }^{4}$ The 17 peers were contacted by e-mail and asked to nominate their "top four" classic or influential articles in the field of MIS. After one e-mail reminder, 15 had responded. Two of the 15 respondents felt they could not nominate any articles, leaving us with 13 peers who identified 24 contributions. One of these 24 nominations was dropped, since it was a book, leaving us with 23 "peer-nominated articles" (see Appendix A for details.) None of the award articles were peer nominated. We refer to the grand total of 36 articles as "exemplar articles" - consisting of the two categories of award articles (13) and peernominated articles (23).

MIS Quarterly is the dominant outlet, having published 20 of the 36 exemplar articles. The 23 peer-nominated articles were published in the journals identified in Table 1 .

As Table 1 shows, MIS Quarterly and Management Science have together published more than 50 percent of the peer-nominated articles. All of the journals are rated as high quality publication outlets by MIS academics (AIS World MIS Journal Rankings ${ }^{5}$ ). These journals are also predominately published in the United States.

\section{Step 2: Locating the Journals Citing Our 36 MIS Exemplar Articles}

In this activity, we looked at the 36 exemplar articles and where they were cited in other (articles in) journals. The social citation index was used for this purpose; it is the dominant, authoritative source for scientific research. In all, 421 journals were identified as having articles citing one or more of the 36 exemplar articles.

${ }^{4} \mathrm{We}$ do not claim that our list of peers is indisputable. Some of the peers requested anonymity with regard to participation, article nominations, and comments. Therefore, peer names are not made available.

${ }^{5}$ Available at http://www.isworld.org/csaunders.rankings.htm (accessed March 12, 2008). 
Our data are best represented in the form of a large table: with the 36 exemplar articles (columns) and the 421 journals, representing articles, that cited these exemplar articles (rows). The intersecting cell for each entry shows the number of times that $\mathrm{X}$ journal has cited Y exemplar article from the time of publication until the end of data collection, August 2006. The raw data are available from the authors.

\section{Step 3: Preparing Data for Keyword Analysis of Exemplar Articles}

Given Proposition 1, which asserts that "a set of exemplar MIS articles covers a wide range of themes," we performed a keyword analysis of the exemplar articles. We created a table, with 149 keywords (rows) and our 36 exemplar articles (columns). In the analysis section we report on common terminology and on the frequency of use.

\section{Step 4: Preparing the Citation Life Cycle Data}

Once the table of exemplar articles and journals citing these exemplars was complete, we attempted to "roll up" the data for citation frequency, according to time periods. We attempted an analysis based on a five year increment, as well as an analysis based on a shorter period of one year. Subsequently, we settled on a middle ground - a three year increment. The three year period allowed us sufficient detail to see the development patterns occurring over time, without excessive granularity. By necessity, in our analysis, more recent exemplars have an abbreviated history.

\section{ANALYSIS}

Proposition 1 postulates that the 36 exemplar MIS articles would cover a wide range of themes. Our analysis of keywords demonstrates the wide variety of topics and themes that are dealt with in the exemplar articles. A total of 149 unique keywords were identified, with minimal overlap of 1.2 occurrences. Only seven keywords occur three times. Moreover, the keywords which occur most often are generic in nature (e.g., management information systems, case study, information technology, management, and systems analysis).

Inspection of article titles (see Appendix A) and abstracts shows that each article addresses a separate issue. In fact, the diversity is so great that no obvious patterns or threads are evident. We find that Proposition 1 is strongly supported. It is possible that the field of MIS is not diverse but rather our methods for selection of exemplar MIS articles have lead us to this result. We cannot adjust for the bias but simply observe that none of the articles in our sample were nominated by more than one source (award article or peer). If some agreement on exemplar articles existed, some degree of overlap in nominations would have occurred. The lack of multiple, overlapping nominations strengthens our belief that accepting Proposition 1 is correct.

According to Kronman (2007), the average expected life time for a journal article (as expressed through the citations made to the article), is 11 years. Since an exemplar 
is "outstanding" by definition, our Proposition $2 \mathrm{a}$ asserts that the lifetime is expected to exceed 11 years. We define a citation life time as beginning with the exemplar's year of publication and ending when no further citations are being made to that exemplar. In addition, since our data collection stopped in 2006, we can only say that our articles of 11 years and younger remain active, and their future citation patterns are unknown.

The 36 exemplar articles range in age from 7 years to 30 years old. Six papers are under 11 years old. (These six articles are excluded from analysis for Proposition 2a because they are under 11 years of age and still active. Had they become inactive they would have been included in the analysis for Proposition 2a.) Of the 30 remaining, only one article of 23 years age became "inactive" - and was no longer being cited as of 2004. Of the same 30, the average number of years of citation activity is 16.7. Thus, the citation life time exceeds eleven years and Proposition 2a is supported.

Overall, it is important to note that the number of citations made to the 36 exemplars increases over time (the correlation between year of publication and total number of citations made is $r=-0.35$, where $p=0.04)$. The rate of citation activity over time is considered in Proposition $2 \mathrm{~b}$.

Our Proposition $2 \mathrm{~b}$ is focused on the life-cycle patterns of citations in the exemplar articles. We postulate that the dominant life-cycle pattern for an exemplar article will take the form of a bell curve, illustrating the following shape over time: increase in number of citations, plateau or peak, and, finally, decrease. The shape that we predict is different from Kronman's (2007) slope of consistent decline, from year of publication until the end of citation activity.

To detect life-cycle patterns, we required a minimum 12 year period of citation activity (or four increments of three years). Our scrutiny of exemplars with shorter citation life times yielded discrete data points rather than distinctive patterns. As a result, 13 exemplars were omitted from the citation life-cycle analysis (having fewer than four increments of three years). For each of the remaining 23 exemplars, we reviewed the citation data over the 3 year increments. We examined the sequence for each to discern its development over time - and whether the citation data reflected an increase, plateau or peak, and decrease. We were looking for trends or changes of some magnitude (a minimum of 10 percent change between neighboring values). This analysis was largely quantitative; however, it was necessary to interpret permutations of change. For example, in some instances, we saw small differences in numerical value and we were reluctant to label these as an increase or decrease. Similarly, in a string of values such as 25,14 , and 25 , we elected to interpret this as a plateau rather than as a decrease followed by an increase.

For the most part, we find that Proposition $2 b$ is supported. The results of the analysis demonstrate that 18 out of the 23 exemplars follow this bell-shaped pattern. Among the five exceptions, we observed two variations. Most notably, four articles enjoyed a sustained increase in citation activity throughout their life cycles, up until 2006. Among these four is Daft and Lengel's article from 1986, which is by far the most widely cited of all the exemplars, with 712 citations over a period of 21 years. The final variation consists of one exemplar with a total of 9 citations over 23 years, represented in a long plateau pattern.

Our Proposition 2c states that within the set of 36 exemplars, we expect that articles that reflect conceptual contributions (e.g., theory and research methods) will be cited more frequently than articles that treat contemporary or hot issues (e.g., specific approaches and 
Table 2. Summary of Propositions

\begin{tabular}{|l|l|l|}
\hline $\begin{array}{c}\text { Prop. } \\
\#\end{array}$ & \multicolumn{1}{|c|}{ Proposition Text } & \multicolumn{1}{|c|}{$\begin{array}{c}\text { Test } \\
\text { Result }\end{array}$} \\
\hline P1 & A set of exemplar MIS articles will cover a wide range of themes. & Supported \\
\hline P2a & $\begin{array}{l}\text { The average expected lifetime for a journal article (as expressed } \\
\text { through the citations made to the article), is 11 years. Since an } \\
\text { exemplar is outstanding by definition, the average lifetime is expected } \\
\text { to exceed 11 years. }\end{array}$ & Supported \\
\hline P2b & $\begin{array}{l}\text { The dominant life cycle pattern for an exemplar article will take the } \\
\text { form of a bell curve, illustrating the following shape over time: } \\
\text { increase in number of citations, plateau/peak, and, finally, decrease. }\end{array}$ & $\begin{array}{l}\text { Largely } \\
\text { supported }\end{array}$ \\
\hline P2c & $\begin{array}{l}\text { Within the set of exemplars, we expect that articles that reflect } \\
\text { conceptual contributions (e.g., theory and research methods) will be } \\
\text { cited more frequently than articles that treat contemporary or "hot" } \\
\text { issues (e.g., specific approaches and methods in consulting, or } \\
\text { technology platforms and environments). }\end{array}$ & $\begin{array}{l}\text { Not } \\
\text { supported }\end{array}$ \\
\hline P2d & $\begin{array}{l}\text { Within the set of exemplars, we expect that articles that reflect } \\
\text { conceptual contributions will have a longer lifetime of citation activity } \\
\text { than exemplars that treat contemporary or hot issues. }\end{array}$ & Supported \\
\hline
\end{tabular}

methods in consulting, or technology platforms and environments). We used the title, abstract, and keywords from each exemplar to decide upon its orientation-whether conceptual or contemporary. This process of inspection resulted in a determination of 25 conceptual and 11 contemporary exemplars. The one way ANOVA test yielded an f value $=1.69$, where $\mathrm{p}=0.20$. Consequently, Proposition $2 \mathrm{c}$ is not supported.

The authors formulated Proposition $2 \mathrm{~d}$ to investigate whether exemplars that reflected conceptual contributions would have a longer lifetime of citation activity than exemplars that treated contemporary or hot issues. The result of this one way ANOVA yielded an $\mathrm{f}$ value $=4.93$, where $\mathrm{p}=0.03$. The mean value for conceptual articles is 17.6 years, and the mean value for contemporary articles is 12.6 years.

The propositions and test results are summarized in Table 2.

\section{DISCUSSION}

The present study has met with many challenges. Our approach to the identification of exemplar MIS articles may be biased. MIS Quarterly may have selected its articles of the year for any number of reasons. A similar concern also applies to the peer nominations. Peers were not chosen by an expert panel; rather, they are a convenience sample. More profoundly, the present effort builds on the assumption that there exists, at least to some degree, a unified field called MIS - and that we are capable of making judgments about it based on exemplars and associated citation activity.

As we have indicated, there is a small community conducting and evaluating citation research. Starbuck (2007) investigates the citations of papers published between 1981 and 2004 in 509 journals and finds an average of 0.8 citations per paper in business and 
management and of 0.7 in business finance. Hence, much academic research is not contributing in intended ways to science (Rynes et al. 2001; Van de Ven 2007). In an attempt to measure MIS "research importance," Loebbecke et al. (2007) report on the average number of citations per article, in six journals, from 1996 to 2005. The total number of articles in their dataset is 1,178. They find that the articles in MISQ have the greatest number of citations; however, these are still surprisingly few over the 10 year period $(\mathrm{MISQ}=21.8, \mathrm{ISR}=14.5, \mathrm{EJIS}=4.5, \mathrm{ISJ}=3.8, \mathrm{JSIS}=3.7$ and $\mathrm{JIT}=3.0$ ).

Van de Ven (2007) supports the position that academics rarely cite each others' work. More generally, he extends this argument and asserts that the gulf between science and practice is widening. On the one hand, scientists fail to put their knowledge into practice, and on the other hand, managers are not taking responsibility for seeking out pertinent literature or reflecting and recording the value and utility of their own lessons for applied research. He concludes that "organizations are not learning fast enough to keep up with changing times" (p. 2).

The present study uses exemplar articles as its sample. However, we are able to compare and contrast our findings with that of others conducting citation research on publications, more broadly, in MIS and the social sciences (e.g., Culnan and Swanson 1986; Kronman 2007; Loebbecke et al. 2007; Starbuck 2007; Vessey et al. 2002, 2005). Our exemplars appear to have greater impact than is found in these other studies. The total number of citations made to the exemplars is, on average, 125.2 (1977-2006). We found that only one of our exemplars had entered an inactive period (no longer being cited). The remaining 35 exemplars are still being cited, and their lifetime extends into the future. At the outset, we knew that the exemplars were outstanding by definition - by virtue of the awards or peer nominations that they received. As a result of our analysis and comparisons, we can confirm that they are also outstanding in their impact.

We have found that citation patterns are rarely investigated as they evolve over time. In addition, the pattern over time is more complex than acknowledged. The bell shape that we found depicts a more nuanced transformation than is reflected in a simple linear decline (Kronman 2007). For example, we discovered that sometimes plateaus persist for a long period and may incorporate smaller modulations and fluctuations. Also noteworthy: several exemplars show a consistent pattern of increased citation activity, as is dramatically portrayed in the case of Daft and Lengel (1986).

We discovered that conceptual and contemporary exemplars are not significantly different with respect to the volume/frequency of citation activity. However, conceptual studies endure and have a longer lifetime of citation activity than contemporary studies. Logically, the contemporary exemplars may have a more limited and concentrated use - in light of their being focused on hot topics. In circumstances like this, the whole pattern of citation activity may be compressed-incorporating a quicker rise in the number of citations and then a faster fall. Future research is needed to further explore the distinction between conceptual and contemporary articles.

Additionally, to better understand the role that citation plays in research, it would be useful to conduct studies that combine citation and classification methods. This would help us to understand the different circumstances under which articles are cited - whether for background, to establish credibility, or as an essential element in formulating the research. We can only understand so much about citation activity by counting things. 


\section{CONCLUSIONS}

The present research examines the role of MIS exemplar articles through the lens and method of citation analysis. The 36 exemplar articles, representing outstanding MIS research contributions, is a convenience sample. We have no explicit definition of "exemplar MIS article" characteristics. Rather, our acceptance of MIS Quarterly award articles and peer nominations is an example of referring judgment to other authoritative sources without control over selection procedure or evaluation criteria.

This paper represents the first phase of our research into MIS and its reference disciplines as revealed through MIS exemplars and their citation patterns. Our findings are limited to the exemplars and their citations, and we do not address the matter of referencing disciplines or subfields. This is the focus of the next phase of the research. In this initial phase, we have found that our MIS exemplars do, indeed, cover a wide range of themes. This aligns with established views: many have already addressed the matter of diversity in MIS - and its promise and pitfalls. Some hanker for a core while others view the wide range of ideas as a healthy sign of possibilities, and assert that we must innovate and allow "many flowers to bloom." However, the question remains: When is the level of diversity so extreme that dialogue becomes noise? When is openness counterproductive?

We discovered that the average lifetime for an exemplar article (as expressed through the citations made to the article) is 17 years, compared with an 11 year expected life time, in general, for journal articles. We also ascertained that the dominant life-cycle pattern for an exemplar takes the form of a bell curve, illustrating an increase in the number of citations, followed by a plateau/peak, and, finally, a decrease in the number of citations. In terms of exemplar type, we refuted the proposition that articles that were conceptual in nature would be cited more frequently than articles treating contemporary or hot issues. However, we were able to confirm that conceptual contributions have a longer lifetime of citation activity than contemporary exemplars.

In summary, citation analysis is largely objective, factual, and based on data. However, interpretation is required in framing the research questions and facts, and in analyzing and communicating the results. This method offers a single, powerful lens on the dynamics of the discipline, but it is also a partial view. We recognize that, by itself, citation research is insufficient to characterize the workings of the discipline - as it does not come to grips with the substantive content that makes up the datasets and dialogue. To date, citation analysis has been employed to a limited extent since it is difficult and cumbersome to perform. The advent of tools and electronic databases offers dramatic opportunity for conducting this type of research in the future.

\section{Acknowledgments}

The authors would like to thank Ira Monarch, Sheila Rosenthal, and Ronald Weber for their helpful suggestions and support on earlier versions of this article. 


\section{References}

Agarwal, R., and Lucas, Jr., H. C. 2005. "The Information Systems Identity Crisis: Focusing on High-Visibility and High-Impact Research," MIS Quarterly (29:3), pp. 381-398.

Alavi, M., and Carlson, P. 1992. "A Review of MIS Research and Disciplinary Development," Journal of Management Information Systems (8:4), Spring, pp. 45-62.

Avison, D., Fitzgerald, G., and Powell, P. 2001. "Reflections on Information Systems Practice, Education, and Research: 10 Years of the Information Systems Journal," Information Systems Journal (11:1), pp. 3-22.

Banville, C., and Landry, M. 1989. "Can the Field of MIS be Disciplined?," Communications of the ACM (32:1), pp. 48-60.

Baskerville, R. L., and Meyers, M. D. 2002. "Information Systems as a Reference Discipline," MIS Quarterly (26:1), pp. 1-14.

Bauer, K., and Bakkalbasi, N. 2005. "An Examination of Citation Counts in a New Scholarly Communication Environment," D-Lib Magazine11 (9), September (available at http://www. dlib.org//dlib/september05/bauer/09bauer.html; accessed March 12, 2008).

Benbasat, I., and Weber, R. 1996. "Research Commentary: Rethinking 'Diversity' in Information Systems Research,” Information Systems Research (7:4), pp. 389-399.

Benbasat, I., and Zmud, R.W. 2003. "The Identity Crisis Within the IS Discipline: Defining and Communicating the Discipline's Core Properties," MIS Quarterly (27:2), pp. 183-194.

Crane, D. 1972. Invisible Colleges: Diffusion of Knowledge in Scientific Communities, Chicago: University of Chicago Press.

Cheon, M. J., Grover, V., and Sabherwal, R. 1993. "The Evolution of Empirical Research in IS: A Study in IS Maturity," Information \& Management (24:3), pp. 107-119.

Culnan, M. 1986. "The Intellectual Structure of Management Information Systems, 1972-1982: A Co-citation Analysis," Management Science (32:2), pp. 156-172.

Culnan, M. J., and Swanson, E. B. 1986. "Research in Management Information Systems, 1980-1984: Points of Work and Reference," MIS Quarterly (10:3), pp. 289-302.

Daft, R. L., and Lengel, R. H. 1986. "Organizational Information Requirements: Media Richness and Structural Design," Management Science (32:5), pp. 554-571.

Davis, G. B. 2000. "Information Systems Conceptual Foundations: Looking Backward and Forward," in Organizational and Social Perspectives on Information Technology, R. Baskerville, J. Stage, and J. I. DeGross (eds.), Norwell, MA: Kluwer Academic Publishers, pp. 61-82.

Garfield, E. 1987. "Citation Data is Subtle Stuff: A Primer on Evaluating a Scientist's Performance," The Scientist (1:19), April, pp. 229-230.

Grover, V., Ayyagari, R., Gokhale, R., Lim, J., and Coffey, J. 2006a. "A Citation Analysis of the Evolution and State of Information Systems within a Constellation of Reference Disciplines," Journal of the Association for Information Systems (7:5), May, pp. 270-324.

Grover, V., Ayyagari, R., Gokhale, R., Lim, J., and Coffey, J. 2006b. "About Reference Disciplines and Reference Differences: A Critique of Wade et al.," Journal of the Association for Information Systems (7:5), May, pp. 336-350.

Holsapple, C. W., Johnson, L. E., Manakyan, H., and Tanner, J. 1994. "Business Computing Research Journals: A Normalized Citation Analysis," Journal of Management Information Systems (11:1), Summer, pp. 131-140.

Ives, B., Parks, M. S., Porra, J., and Silva, L. 2004. "Phylogeny and Power in the IS Domain: A Response to Benbasat and Zmud's Call for Returning to the IT Artifact," Journal of the Association for Information Systems (5:3), March, pp.108-124.

Jacso, P. 2005. "Google Scholar and the Scientist," available at http://www2.hawaii.edu/ jacso/ extra/gs/; accessed March 12, 2008. 
Katerattanakul, P., Han, B., and Rea, A. 2006. "Is Information Systems a Reference Discipline," Communications of the ACM (49:5), pp. 114-118.

Katerattanakul, P., and Hong, S. 2003. "Quality and Knowledge Contribution of MISQ: A Citation Analysis," Communications of the Association for Information Systems(11), pp. 271-288.

Kronman. U. 2007. "Bibliometrics - What, Why, and How?," available at http://infomgt.bi.no/ research/tor-is-concepts/Kronman-Ulf-Bibliometrics.pdf; accessed March 12, 2008.

Kuhn, T. S. 1970. The Structure of Scientific Revolutions ( $2^{\text {nd }}$ ed.), Chicago: The University of Chicago Press.

Larsen, T. J. 1998. "Information Systems Innovation: A Framework for Research and Practice," in Information Systems Innovation and Diffusion: Issues and Direction, T. J. Larsen and E. McGuire (eds.), Hershey, PA: Idea Group Publishing, pp. 411-434.

Larsen, T. J., and Levine, L. 2005. "Searching for Management Information Systems: Coherence and Change in the Discipline," Information Systems Journal (15:4), pp. 357-381.

Larsen, T. J., and Levine, L. 2007. "The Identity, Dynamics, and Diffusion of MIS," in Organizational Dynamics of Technology-Based Innovation: Diversifying the Research Agenda, T. McMaster, T. Wastell, D. Ferneley, and J. I. DeGross (eds.), New York: Springer, pp. 163-177.

Loebbecke, C., Berthod, O., and Huyskens, C. 2007. "Research Importance in the Information Systems Field: A Citation Analysis," in Proceedings of the $28^{\text {th }}$ International Conference on Information Systems, Montreal, Canada, December 9-12, pp. 1-15.

Lyytinen, K., and King, J. L. 2004. "Nothing at the Center?: Academic Legitimacy in the Information Systems Field," Journal of the Association for Information Systems (5:6), June, pp. 220-246.

Monod, E., and Boland, R. J. 2007. "Editorial: Special Issue on Philosophy and Epistemology: A 'Peter Pan Syndrome'?," Information Systems Journal (17:2), pp. 133-141.

Mylonopoulos, N. A., and Theorharakis, V. 2001. "Global Perceptions of IS Journals," Communications of the ACM (44:9), pp. 29-33.

Myers, M. D. 2002. "The IS Core-VIII: Defining the Core Properties of the IS Discipline: Not Yet, Not Now," Communications of the Association for Information Systems (12), pp. 582-587.

Orlikowski, W. J., and Baroudi, J. J. 1991. "Studying Information Technology in Organizations: Research Approaches and Assumptions," Information Systems Research (2:1), pp. 1-28.

Orlikowski, W. J., and Iacono, C. S. 2001. "Research Commentary: Desperately Seeking the 'IT' in IT Research-A Call to Theorizing the IT Artifact," Information Systems Research (12:2), June, pp. 121-134.

Perkel, J. M. 2005. "The Future of Citation Analysis," The Scientist (19:20), October (available at http://www.garfield.library.upenn.edu/papers/futureofcitationanalysists102405.pdf).

Pfeffer, J. 1993. "Barriers to the Advance of Organizational Science: Paradigm Development as a Dependent Variable," Academy of Management Review (18:4), pp. 599-620.

Pfeffers, K., and Ya, T. 2003. "Identifying and Evaluating the Universe of Outlets for Information Systems Research: Ranking the Journals," The Journal of Information Technology Theory and Application (5:1), pp. 63-84.

Ritzer, G. 1975. "Sociology: A Multiple Paradigm Science," The American Sociologist (10), August, pp. 156-167.

Robey, D. 1996. "Research Commentary: Diversity in Information Systems Research: Threat, Promise, and Responsibility," Information Systems Research (7:4), pp. 400-408.

Rynes, S. L., Bartunek, J. M., and Daft, R. L. 2001. “Across the Great Divide: Knowledge Creation and Transfer Between Practitioners and Academics," Academy of Management Journal (44:2), pp. 340-355.

Small, H. 1973. "Co-citation in the Scientific Literature: A New Measure of the Relationship Between Two Documents," Journal of the American Society for Information Science, July-August, 265-269. 
Small, H. 1978. "Cited Documents as Concept Symbols," Social Studies of Science (8:3), August, pp. 327-340.

Small, H. 1980. "Co-citation Context Analysis and the Structure of Paradigms," The Journal of Documentation (36:3), pp. 183-196.

Starbuck, W. H. 2007. "What the Numbers Mean,” available at http://pages.stern.nyu.edu/ $\sim$ wstarbuc/whatmean.html; accessed March 12, 2008).

Straub, D. 2006. "The Value of Scientometric Studies: An Introduction to a Debate on IS as a Reference Discipline," Journal of the Association for Information Systems (7:5), May, pp. 241-246.

Van de Ven, A. H. 2007. Engaged Scholarship: A Guide for Organizational and Social Research, Oxford, England: Oxford University Press.

Vessey, I., Ramesh, V., and Glass, R. L. 2002. "Research in Information Systems: An Empirical Study of Diversity in the Discipline and Its Journals," Journal of Management Information Systems (19:2), Fall, pp. 129-174.

Vessey, I., Ramesh, V., and Glass, R. L. 2005. “A Unified Classification System for Research in the Computing Disciplines," Information \& Software Technology (47:4), pp. 245-255.

Wade, M., Biehl, M., and Kim, H. 2006a. "Information Systems is 'Not' a Reference Discipline (And What We Can Do About It)," Journal of the Association for Information Systems (7:5), May, pp. 247-268.

Wade, M., Biehl, M., and Kim, H. 2006b. "If the Tree of IS Knowledge Falls in a Forest, Will Anyone Hear? A Commentary on Gover et al.," Journal of the Association for Information Systems (7:5), May, pp. 326-334.

Walstrom, K. A., and Hardgrave, B. C. 2001. "Forums for Information Systems Scholars: III," Information \& Management (39:2), pp. 117-124.

Weber, R. 1987. "Toward a Theory of Artifacts: A Paradigmatic Base for Information Systems Research," Journal of Information Systems, Spring, pp. 3-19.

Weber, R. 2003. "Editor's Comments: Still Desperately Seeking the IT Artifact," MIS Quarterly (27:2), pp. iii-xi.

Whinston, A. B., and Geng, X. 2004. "Operationalizing the Essential Role of the Information Technology Artifact in Information Systems Research: Gray Area, Pittfalls, and the Importance of Strategic Ambiguity," MIS Quarterly (28:2), pp. 149-159.

\section{About the Authors}

Tor J. Larsen holds an MA in Systems Thinking from the University of Lancaster, England (1975) and earned his Ph.D. in Management Information Systems (MIS) from the University of Minnesota (1989). He is professor in Knowledge Management and holds the position of Senior Vice President at the Norwegian School of Management. He has served as an associate editor for MIS Quarterly. Dr. Larsen has published widely, for example in Information \& Management, Journal of MIS, and Information Systems Journal. He is a member of AIS and IFIP WG8.2 and WG8.6. In 2006, he was program co-chair for the WG8.6 Working Conference on the "Transfer and Diffusion of IT for Organizational Resilience.” Dr. Larsen's research interests are in the areas of managers' use of information, knowledge management, innovation, diffusion, representation, and innovation outcome. He can be reached at Tor.J.Larsen@BI.NO.

Linda Levine is a senior member of the technical staff at Carnegie Mellon University's Software Engineering Institute. Her research focuses on acquisition of software intensive systems, agile software development, system interoperability, diffusion of innovations, and knowledge integration and transfer. She holds a Ph.D. in Rhetoric from Carnegie Mellon University. She is a member of the Association for Information Systems, IEEE Computer Society, National Communication Association, and cofounder and Chair of IFIP Working Group 8.6 on Diffusion, Transfer and Implementation of Information Technology. Contact her at 11@sei.cmu.edu. 


\section{APPENDIX A. LIST OF EXEMPLAR MIS ARTICLES IN OUR SAMPLE}

\section{MIS Quarterly, Article of the Year:}

[1] Klein, H. K., and Myers, M. D. 1999. "A Set of Principles for Conducting and Evaluating Interpretive Field Studies in Information Systems," MIS Quarterly (23:1), pp. 67-94.

[2] Kumar, K., van Dissel, H.G., and Belli, P. 1998. "The Merchant of Prato - Revisited. Toward a Third Rationality of Information Systems," MIS Quarterly (22:2), pp. 199-226.

[3] Ngwenyama, O. K., and Lee, A. S. 1997. "Communication Richness in Electronic Mail: Critical Social Theory and the Contextuality of Meaning," MIS Quarterly (21:2), pp. 145-167.

[4] Hitt, L. M., and Brynfolfsson, E. 1996. "Productivity, Business Profitability, and Consumer Surplus: Three Different Measures of Information Technology Value," MIS Quarterly (20:2), pp. 121-142.

[5] Mukhopadhyay, T., Kekre, S., and Kalathur, S. 1995. "Business Value of Information Technology: A Study of Electronic Data Interchange," MIS Quarterly (19:2), pp. 137-156.

[6] Leidner, D. E., and Jarvenpaa, S. L. 1995. "The Use of Information Technology to Enhance Management School Education: A Theoretical View," MIS Quarterly (19:3), pp. 265-281.

[7] Hess, C. M., and Kemerer, C. F. 1994. "Computerized Loan Origination Systems: An Industry Case Study of the Electronic Markets Hypothesis," MIS Quarterly (18:3), pp. 251-274.

[8] Orlikowski, W. 1993. "Case Tools as Organizational Change: Investigating Incremental and Radical Changes in Systems Development," MIS Quarterly (17:3), pp. 309-340.

\section{MIS Quarterly, SIM Best Article:}

[9] Cooper, B. L., Watson, H. J., and Goodhue, D. L. 2000. "Data Warehousing Supports Corporate Strategy at First American Corporation," MIS Quarterly (24:4), pp. 547-567.

[10] Roepke, R. P. 2000. "Aligning the IT Human Resource with Business Vision: The Leadership Initiative at 3M," MIS Quarterly (24:2), pp. 327-343.

[11] El Sawy, O. A., Malhotra, A., Gosain, S., and Young, K. M. 1999. "IT-Intensive Value Innovation in the Electronic Economy: Insight from Marshall Industries," MIS Quarterly (23:3), pp. 305-334.

[12] Cross, J., Earl, M. J., and Sampler, J. L. 1997. "Transformation of the IT Function at British Petroleum," MIS Quarterly (21:4), pp. 401-423.

[13] Caron, J. R. 1994. "Business Reengineering at CIGNA Corporation," MIS Quarterly (18:3), pp. 233-250.

\section{Peer Nominated Articles:}

[14] Markus, L., and Robey, D. 1988. "Information Technology and Organizational Change: Causal Structure in Theory and Research," Management Science (34:5), pp. 583-598.

[15] DeLone, W., and McLean, E. 1992. "Information Systems Success: The Quest for the Dependent Variable," Information Systems Research (3:1), pp. 60-95. 
[16] Hirschheim, R., and Klein, H. 1989. "Four Paradigms of Information Systems Development," Communication of the ACM (32:10), pp. 1199-1216.

[17] Hammer, M. 1990. "Reengineering Work: Don’t Automate, Obliterate," Harvard Business Review (68:4), July-August, pp. 104-112.

[18] Henderson, J. C., and Venkatraman, N. 1993. "Strategic Alignment: Leveraging Information Technology for Transforming Organizations," IBM Systems Journal (32:1), pp. 4-16.

[19] Myers, M. D. 1997. “Qualitative Research in Information Systems,” MIS Quarterly (21:2), pp. 241-242.

[20] Brancheau, J. C., and Wetherbe, J. C. 1987. "Key Issues in Information Systems Management," MIS Quarterly (11:1), pp.23-45.

[21] Goodhue, D., and Wybo, M. D. 1992. "The Impact of Data Integration on the Cost and Benefits of Information Systems," MIS Quarterly (16:3), pp. 293-311.

[22] Ives, B., and Jarvenpaa, S. L. 1991. "Applications of Global Information TechnologyKey Issues for Management," MIS Quarterly (15:1), pp. 33-49.

[23] Malone, T. W., Yates, J., and Benjamin, R. I. 1987. "Electronic Markets and Electronic Hierarchies," Communications of the ACM (30:6), pp. 484-497.

[24] Lee, A. S. 1989. “A Scientific Methodology for MIS Case Studies,” MIS Quarterly (13:1), pp. 33-50.

[25] Daft, R. L., and Lengel, R. H. 1986. "Organizational Information Requirements: Media Richness and Structural Design," Management Science (32:5), pp. 554-571.

[26] DeSanctis, G., and Gallupe, R. B. 1987. "A Foundation for the Study of Group Decision Support Systems,” Management Science (33:5), pp. 589-609.

[27] Sprague, R. H. 1980. "A Framework for the Development of Decision Support Systems," MIS Quarterly (4:4), pp. 1-26.

[28] Dickson, G. W., Senn, J. A., and Chervany, N. L. 1977. "Research in Management Information Systems: The Minnesota Experiments," Management Science (23:9), pp. 913-923.

[29] Ives, B., Hamilton, S., and Davis, G. B. 1980. "A Framework for Research in ComputerBased Management Information Systems," Management Science (26:9), pp. 910-934.

[30] Boland, Jr., R. J. 1984. "Sense-Making of Accounting Data as a Technique of Organizational Diagnosis," Management Science (30:7), pp. 868-882.

[31] Hirschheim, R., Klein, H. K., and Lyytinen, K. 1996. "Exploring the Intellectual Structures of Information Systems Development: A Social Action Theoretical Analysis," Accounting, Management and Information (6:1/2), pp. 1-64.

[32] Orlikowski, W. J., and Baroudi, J. J. 1991. "Studying Information Technology in Organizations: Research Approaches and Assumptions," Information Systems Research (2:1), pp. 1-28.

[33] Avergou, C., Siemer, J., and Bjørn-Andersen, N. 1999. "The Academic Field of Information Systems in Europe," European Journal of Information Systems (8:2), pp. 136-153.

[34] Markus, L. 1983. "Power, Politics and MIS Implementation," Communications of the ACM (26:6), pp. 430-444.

[35] Bostrom, R. P., and Heinen, J. S. 1977. "MIS Problems and Failures: A Socio-Technical Perspective Part I: Causes," MIS Quarterly (1:3), pp. 17-32.

[36] Davis, G. 1982. "Strategies for Information Requirements Determination," IBM Systems Journal (21:1), pp. 4-30.

[37] ${ }^{6}$ Checkland, P. B., and Scholes, J. 1990. Soft Systems Methodology in Action, West Sussex, England: John Wiley \& Sons, Ltd.

${ }^{6}$ The nomination is a book, hence not found in the social citation index and excluded from the analysis. 